\title{
Comparative Evaluation of Two in -Office Bleaching Agents Using Two Different Light Sources- In Vivo Study
}

\author{
Dr. Sanjyot Mulay ${ }^{1}$, Dr Apurva Band ${ }^{2}$ \\ ${ }^{I}$ (MDS, PG and PHD Guide Department of conservative dentistry and endodontics, D.Y.Patil University,India) \\ ${ }^{2}$ ( III MDS Department of conservative dentistry and endodontics, D.Y.Patil University,India)
}

\begin{abstract}
The purpose of this study was to evaluate and compare the effect of 35\% Hydrogen Peroxide and $35 \%$ Carbamide peroxide in - office bleaching agents using plasma arc and laser light sources on colour change, enamel surface morphology and sensitivity on teeth. -in vivo study

Material and method: This study was carried out on 12 patients in which four groups i.e. $35 \%$ carbamide peroxide and plasma arc (CPP), 35\% carbamide peroxide and laser light source (CPL), 35\% hydrogen peroxide and Plasma arc (HPP), 35\% hydrogen peroxide and laser light source (HPL) were made in all the four quadrants in anterior teeth. Preoperative baseline shade and impression was taken and same was repeated post operatively. After bleaching procedure colour change was evaluated using VITA classic shade guide, change in enamel surface morphology was calculated on epoxy model using contact profilometer and tooth sensitivity was analyzed using VAS scale.

Result: $35 \%$ Carbamide peroxide and plasma arc (CPP) group showed significant colour change followed by $35 \%$ hydrogen peroxide plasma arc (HPP) group, 35\% hydrogen peroxide and lasers (HPL)group and 35\% carbamide peroxide and laser (CPL)group whereas highest change in enamel surface morphology was observed in 35\% hydrogen peroxide and laser light source (HPL) group followed by 35\% carbamide peroxide and laser light source (CPL) group, 35\% hydrogen peroxide plasma arc (HPP) group , 35\% carbamide peroxide plasma arc $(C P P)$ group.

Conclusion: Carbamide peroxide $35 \%$ using plasma arc presented greater colour change as compared to Hydrogen peroxide 35\% using laser light source. Laser light source caused more change in enamel surface morphology as compared to plasma arc.
\end{abstract}

Keywords: Contact profilometry,In- office bleaching, Laser, Plasma arc.

\section{Introduction}

Tooth discoloration is seen commonly due to extrinsic or intrinsic stains. Intrinsic stains can be treated with bleaching, veneers or crowns. The most non invasive and conservative treatment for these stains is tooth bleaching.

Now a days patients demand quick results, so in-office bleaching techniques are getting popular. Till date there are very few in office bleaching agents and light sources available like plasma arc and relatively newly introduced laser light for bleaching purpose.

The efficacy of light activated systems versus non-light activated controls in clinical studies is limited and conflicting. Other factors which can influence tooth bleaching outcome include type of stain, initial tooth colour and age of patient ${ }^{(1)}$

Lasers have recently been introduced as a light source for power bleaching and are not much studied previously. Hence the purpose of this study was to evaluate and compare two different in-office bleaching agents using two different light sources.

\section{Materials And Method}

Twelve patients having teeth shade A3 or darker were selected for the study from outpatient unit of the department of Conservative dentistry and Endodontics. While selecting the patient following inclusion and exclusion criteria was taken into consideration.

Inclusion criteria : Patients from the age group 18yrs to 35yrs, A3 or darker shade of the teeth, healthy periodontium, teeth without restoration, no previous history of bleaching and absence of any tooth sensitivity were selected.

Exclusion criteria were Carious, restorations or cracked teeth, Tetracycline stains, Dental fluorosis, patients with pre-existing tooth sensitivity, smokers, malaligned teeth, pregnant and nursing mother.

Oral prophylaxis was carried out before treatment for all patients and they were given proper oral hygiene maintenance instructions. Pre operative shade selection was done by 3 independent observers using VITA Classic shade guide under standard light conditions, the shades were then assigned as numeric value [Table2.1]. 
Comparative Evaluation Of Two In -Office Bleaching Agents Using Two Different Light .....

\begin{tabular}{|l|l|l|l|l|l|l|l|}
\hline Tab & Value & Tab & Value & Tab & Value & Tab & Value \\
\hline $\mathrm{B} 1$ & 1 & $\mathrm{~A} 2$ & 5 & $\mathrm{~A} 3$ & 9 & $\mathrm{~B} 4$ & 13 \\
\hline $\mathrm{A} 1$ & 2 & $\mathrm{C} 1$ & 6 & $\mathrm{D} 3$ & 10 & $\mathrm{C} 3$ & 14 \\
\hline $\mathrm{B} 2$ & 3 & $\mathrm{C} 2$ & 7 & $\mathrm{~B} 3$ & 11 & $\mathrm{~A} 4$ & 15 \\
\hline $\mathrm{D} 2$ & 4 & $\mathrm{D} 4$ & 8 & $\mathrm{~A} 3,5$ & 12 & $\mathrm{C} 4$ & 16 \\
\hline
\end{tabular}

Table 2.1:Table showing Conversion of Vita Classical Shade Guide Tabs to Numeric Values.

Baseline impression was recorded with maxillary and mandibular anterior teeth using rubber base impression material. These impressions were poured using epoxy resin material, which was prepared by mixing powder and liquid with $0.2 \%$ hardener in it so as to prepare a model.

A split mouth study on maxillary and mandibular anterior teeth was carried in all the four quadrants.

Grouping was done as follows

Each of the 12 patients were randomly divided into 4 quadrants having 3 anterior teeth. Four groups formed were:

$>\quad$ GROUP HPP: $35 \%$ hydrogen peroxide using plasma arc light source.

GROUP HPL: $35 \%$ hydrogen peroxide using laser light source.

$>\quad$ GROUP CPP: $35 \%$ carbamide peroxide using plasma arc light source.

$>\quad$ GROUP CPL: $35 \%$ carbamide peroxide using laser light source.

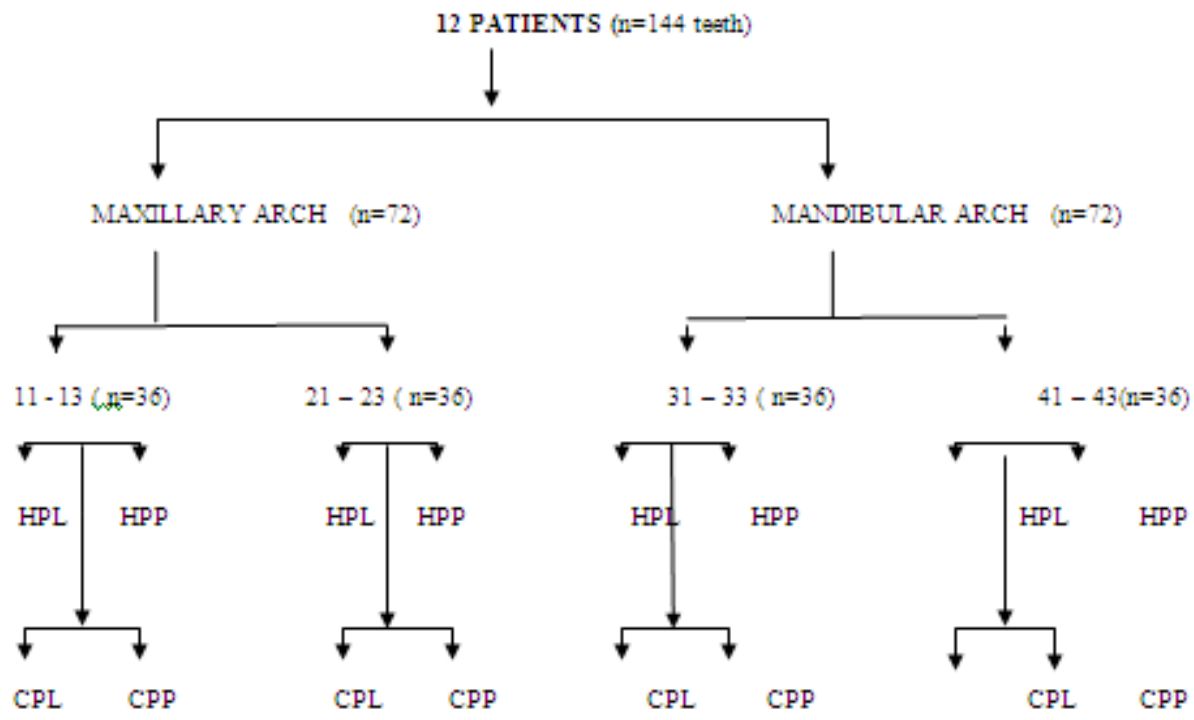

Each arch was isolated and gingival barrier was placed separately from left to right canine region in maxillary and mandibular arch. Bleaching agent was then applied according to the manufacturer's instructions.

- 10 mins for $35 \%$ hydrogen peroxide

- 30 mins for $35 \%$ carbamide peroxide

- 1 to $1.5 \mathrm{~mm}$ thick layer was applied on labial surface.

Respective light source i.e. Plasma arc or Laser light was activated. At the end of treatment, the bleaching agent was rinsed with air water spray for $30 \mathrm{sec}$.

Colour change was evaluated by 3 observers other than operator using classic VITA shade guide under standardized illumination. Tooth color was selected using the Vita Classic shade guide arranged in decreasing order of value: B1, A1, B2, D2, A2, C1, C2, D4, A3, D3,B3, A3.5, B4, C3, A4 and C4. These were then converted to numeric values as given in table 2.1 .

Tooth sensitivity was checked by using three way syringe from a distance of 5 to $10 \mathrm{cms}$ by observer other than operator using tooth sensitivity scale VAS (Visual Analogue Scale) from 1 to 5.

High precision impression was taken immediately after bleaching, using a polyvinyl siloxane based material with double impression technique. Replicas were prepared by pouring the impression with an epoxy resin mixed under vacuum. All replicas were analyzed using contact profilometer. 
Comparative Evaluation Of Two In -Office Bleaching Agents Using Two Different Light .....

III. Observation And Results Figures And Tables

Table 3.1: Comparison of the colour change in the various study groups at various time intervals.

\begin{tabular}{|c|c|c|c|c|c|c|c|c|c|c|c|c|}
\hline \multicolumn{13}{|c|}{ COLOUR CHANGE } \\
\hline \multirow{2}{*}{ sne } & \multirow{2}{*}{ GROUPS } & \multicolumn{2}{|c|}{ Preoperctive } & \multicolumn{2}{|c|}{ Immsdizte } & \multicolumn{2}{|c|}{1 week } & \multicolumn{2}{|c|}{4 weaks } & \multirow{2}{*}{$\begin{array}{l}\text { ANOVA } \\
\text { Fvalue }\end{array}$} & \multirow{2}{*}{ P value } & \multirow{2}{*}{$\begin{array}{c}\text { Post hoc } \\
\text { Bonferroni } \\
\text { result }\end{array}$} \\
\hline & & Mean & SD & Mesm & SD & Mesm & SD & Mesen & $S D$ & & & \\
\hline 1 & $\begin{array}{l}\text { Carbemida } \\
\text { peroxida + } \\
\text { plasma arc }\end{array}$ & 10.32 & 237 & 6.28 & 2.14 & 6.11 & 226 & 6.80 & 191 & 14.403 & $0.000^{*}$ & $\begin{array}{l}1>2^{*} \\
1>3^{*} \\
1>4^{*}\end{array}$ \\
\hline 2 & $\begin{array}{l}\text { Hydrogen } \\
\text { peroxida + } \\
\text { plesme arc }\end{array}$ & 8.89 & 2.34 & 5.52 & 1.40 & 498 & 1.12 & 5.76 & 0.66 & 22.269 & $0.000^{*}$ & $\begin{array}{l}1>2 * \\
1>3 * \\
1>4 *\end{array}$ \\
\hline 3 & $\begin{array}{c}\text { Hydrogen } \\
\text { peroxide+ } \\
\text { laser }\end{array}$ & 9.89 & 2.55 & 6.65 & 2.60 & 6.80 & 285 & 753 & 236 & 5.863 & $0.001^{*}$ & $\begin{array}{l}1>2^{\circ} \\
1>3^{\circ}\end{array}$ \\
\hline 4 & $\begin{array}{c}\text { Carbamide } \\
\text { peroxide } \\
\text { laser }\end{array}$ & 10.29 & 2.02 & 752 & 2.12 & 7.73 & 224 & 7.47 & 1.81 & 7.731 & $0.000^{*}$ & $\begin{array}{l}1>2^{*} \\
1>3^{*} \\
1>4^{*}\end{array}$ \\
\hline & $\begin{array}{l}\text { ANOVA } \\
\text { Fvalue }\end{array}$ & & & & & & & & & & & \\
\hline & Pvalua & 02 & & & & & & & & & & \\
\hline Pos: & $\begin{array}{l}\text { noc Bonferroni } \\
\text { result }\end{array}$ & & & & & & & & & & & \\
\hline
\end{tabular}

Tables 3.2: Comparison of the Surface Roughness of various study groups.

\begin{tabular}{|c|c|c|c|c|c|c|c|}
\hline \multicolumn{8}{|c|}{ SURFACE ROUGHNESS (microns) } \\
\hline \multirow{2}{*}{ s.no } & \multirow{2}{*}{ groups } & \multicolumn{2}{|c|}{ Preoperative } & \multicolumn{2}{|c|}{ Postoperative } & \multirow{2}{*}{$\mathrm{t}$ value } & \multirow{2}{*}{$P$ value } \\
\hline & & Mean & $\mathrm{SD}$ & Mean & $\mathrm{SD}$ & & \\
\hline 1 & Carbamide peroxide + plasma arc & 0.303 & 0.153 & 0.436 & 0.182 & -4.094 & $0.00 *$ \\
\hline 2 & Hydrogen peroxide + plasma arc & 0.234 & 0.129 & 0.380 & 0.127 & -5.954 & $0.00^{*}$ \\
\hline 3 & Carbamideperoxide+laser & 0.338 & 0.142 & 0.560 & 0.142 & -8.098 & $0.00^{*}$ \\
\hline 4 & Hydrogen peroxide + laser & 0.248 & 0.090 & 0.442 & 0.053 & -13.627 & $0.00 *$ \\
\hline & $\begin{array}{l}\text { ANOVA } \\
\text { F value }\end{array}$ & \multicolumn{2}{|c|}{7.479} & \multicolumn{2}{|c|}{17.030} & & \\
\hline & $P$ value & 0.0 & & & $00^{*}$ & & \\
\hline \multicolumn{2}{|r|}{ Post hoc bonferroni result } & $\begin{array}{l}1> \\
3> \\
3>\end{array}$ & & $\begin{array}{l}3 y \\
3 y \\
3 y\end{array}$ & $\begin{array}{l}1^{*} \\
2^{*} \\
4^{*}\end{array}$ & & \\
\hline
\end{tabular}




\section{Discussion}

In this study most commonly used in office bleaching agents 35\% Hydrogen Peroxide and $35 \%$ Carbamide peroxide were used ${ }^{(2)}$. As light activation of bleaching agent show better results in comparatively less time, plasma arc and Laser light sources were used. Lasers have been recently introduced in cosmetic procedures including bleaching and very less documented research material is available in relation to Nd-YAG lasers.

From a scientific point of view, data on mechanisms of action and efficacy of laser, light and heatactivated dental bleaching is still limited. Hydrogen peroxide has a low molecular weight and, therefore, diffuses through the organic matrix of the enamel and dentin. During bleaching, hydrogen peroxide creates an oxygenation process on the tooth surface that acts to break the bonds of staining molecules in tooth structure. When combined with a light source, the process of tooth bleaching may be accelerated. ${ }^{(3)}$ It is thought the light triggers a quicker degradation of the peroxide into its reactive components including oxygen free radicals.

According to study conducted by Bernard JK et al light source used in bleaching acts as a catalyst only $^{(3)}$. Cadenaro $\mathrm{M}$ et al studied high concentrations of bleaching agents and showed that their use is safe which maintains normal healthy tooth structure ${ }^{(4)}$.

According to studies conducted by Hegedüs et al using lower concentration of hydrogen peroxide ${ }^{(5)}$ and Rodrigues et al. using $37 \%$ carbamide peroxide ${ }^{(6)}$ concluded that most of the bleaching agents cause alterations on the enamel surface and decrease in microhardness some causing grooves on the surface and even affect the inner surface.

In this study it was observed that CP $35 \%$ and HP $35 \%$ showed significant colour change using both plasma arc and laser light source. All four study groups i.e. CPP (Carbamide peroxide 35\% using Plasma arc light source), HPP(Hydrogen peroxide 35\% using Plasma arc light source), CPL( Carbamide peroxide 35\% using Laser light source), HPL( Hydrogen peroxide 35\% using Laser light source) showed slight colour relapse or reversal of shade at one week and four week post operative period. This could be because of immediate dehydration effect after bleaching showing marked lightening effect. However slow rehydration of tooth in the follow up period could be seen as alteration of tooth shade. This observation is in agreement with the study done by Kugel et.al. ${ }^{7}$

CPP showed greater colour change as compared to HPP as carbopol in carbamide peroxide retains bleaching agent for longer time on the tooth surface thus has a sustained release ${ }^{8}$. The time of application for Carbamide peroxide bleaching agent is greater than that of Hydrogen peroxide enhancing slow release of peroxides which shows better results. This observation is in agreement with the study done by Zekonis et. al. ${ }^{9}$

In order to increase light absorption, some bleaching products are mixed with specific colorants, eg, an orange-red color increases the absorption of blue light. In $35 \%$ Hydrogen peroxide addition of small silica particles in the nanometer or lower micrometer scale gives this product a bluish appearance and increases the absorption of red and infrared light. The energy required for photolysis can only be provided by high frequency light as lasers ${ }^{10}$. Hence HPL showed greater colour change as compared to CPL.

Laser Whitening Gel is a unique mix of laser activated Crystals integrated into a gel of highly processed Fumed Silica and 35\% Hydrogen Peroxide. This translucent, semi-viscous bleaching gel is applied to the teeth and a high intensity light source (laser light) is used to activate the Crystals to absorb the thermal energy from the light and allowing better dissociation of the oxygen to better penetrate the enamel matrix and increase the lightening effect on the teeth ${ }^{11}$. The bleaching agents used in this study did not contain fumed silica particles hence Plasma arc light source showed better colour change than laser light source.

In this study it was observed that $35 \%$ carbamide peroxide and 35\% Hydrogen peroxide showed significant surface roughness using both plasma arc and laser light source. Surface roughness caused by laser light source was greater than surface roughness caused due to plasma arc light source which could be due to greater penetrability of laser light source into dental hard tissue ${ }^{12}$.

$35 \%$ Carbamide peroxide showed greater surface roughness as compared to $35 \%$ Hydrogen peroxide. $\mathrm{Nd}-\mathrm{YAG}$ lasers shows lower absorption in water ${ }^{13}$. As carbamide peroxide has greater content of water and is soluble in water where as hydrogen peroxide is miscible in water the lasers were directly focused on tooth surface leading to surface roughness ${ }^{14}$.

Carbamide peroxide $10 \%$ yields $3.6 \%$ of hydrogen peroxide so $35 \%$ carbamide peroxide would yield $12.6 \%$ of hydrogen peroxide ${ }^{15}$. Bleaching agents are acidic in $\mathrm{pH}$. The products used in this study were $35 \%$ carbamide peroxide and $35 \%$ hydrogen peroxide. As concentration of hydrogen peroxide has increased, irrespective of using light source i.e. plasma arc which has less intensity compared to lasers HPP group showed significantly greater surface roughness than CPP group. This observation is in agreement with the studies performed by Attin et.al. 1997; Smidt et.al 1998; Rodrigues et.al.2001. ${ }^{16,17}$

In this study postoperative tooth sensitivity was not observed, in study performed by Matis BA and Cochran MA in 2007 also found no tooth hypersensitivity using 16\% carbamide peroxide and Bernardon et.al. in 2010 found that $35 \%$ hydrogen peroxide leads to hypersensitivity in teeth ${ }^{18,19}$ 


\section{Conclusion}

Under the limitations of this study, following conclusions can be drawn.

1. Carbamide Peroxide 35\% and Hydrogen Peroxide 35\% showed significant colour change using both plasma arc and laser light sources.

2. Greater colour change was observed with Carbamide peroxide $35 \%$ using plasma arc source followed by Hydrogen peroxide $35 \%$ using plasma arc. Comparatively less colour change was observed with $35 \%$ hydrogen peroxide using laser light source followed by $35 \%$ carbamide peroxide using laser light source. The result was statistically significant.

3. Maximum change in enamel surface morphology (surface roughness) was observed with $35 \%$ Carbamide peroxide using laser light source followed by 35\% Hydrogen Peroxide using laser light, followed by 35\% Hydrogen Peroxide using plasma arc. The least surface roughness was observed with 35\% Carbamide peroxide using plasma arc light source. The difference was statistically significant.

4. Neither Carbamide Peroxide 35\% or Hydrogen Peroxide 35\% when used with plasma arc or laser light source caused immediate or delayed post operative sensitivity during the follow-up period of upto 4 weeks.

\section{Acknowledgement}

The authors are indebted to mr. Bhagat for providing contact profilometer for our study and Dr. Simpy for statistical analysis

\section{References}

[1]. Leonard RH, Haywood VB, Eagle JC, Garland GE, Caplan DJ, Matthews KP, et al. Nightguard vital bleaching of tetracycline-stained teeth: 54 months post treatment. Journal of Esthetic Dentistry 1999;11:265-77.

[2]. Johnny Fearon Tooth whitening: concepts and controversies INTERNATIONAL DENTISTRY SA 2007; 11- 2:31-38.

[3]. M. Suleiman An Overview of Bleaching Techniques:1. History, Chemistry, Safety and Legal Aspects. Dent Update 2004; 31: 608616

[4]. Andrew Joiner. The bleaching of teeth: A review of the literature journal of dentistry.2006; $412-419$

[5]. Hegedüs, C., Bistey, T., Flora-Nagy, E., Keszthelyi, G., \& Jenei, A. An atomic force microscopy study on the effect of bleaching agents on enamel surface. J Dent. 1999; 27:509-515.

[6]. Lopes GC, Bonissoni L, Baratieri LN, Vieira LC, Monteiro S Jr. Effect of bleaching agents on the hardness and morphology of enamel.J Esthet Restor Dent. 2002;14(1):24-30.

[7]. Kugel G, Petkevis J, Gurgan S, Doherty E. Separate whitening effects on enamel and dentin after fourteen days. J Endod 2007 Jan;33(1):34-7.

[8]. Goldstein RE, Garber DA. Complete dental bleaching. Quintessence; 1995.

[9]. Zekonis et. al. Clinical evaluation of In-office and At- home bleaching treatment. Oper.Dent 2003; 28(2): 114-121.

[10]. Roeland J. G. De Moora, Katrien Vanderstrichtb. The Use of the KTP Laser, an Added Value for Tooth Bleaching J Oral Laser Applications 2009; 9: 219-226.

[11]. Hegde Mithra N., Shetty Krishna R., Shetty Shishir. Overview of in-office bleaching of vital teeth. IRJP 2012; 3 (11):12-16

[12]. Roeland J. G. De Moora, Katrien Vanderstrichtb. The Use of the KTP Laser, an Added Value for Tooth Bleaching J Oral Laser Applications 2009; 9: 219-226.

[13]. Brotherton Boron BJ. Inorganic chemistry encyclopedia of inorganic chemistry. Bruce King, John Wiley \& Sons; 1994

[14]. Wolfgang Buchallaa,b, Thomas Attina,b. External bleaching therapy withactivation by heat, light or laser-A systematic review DENTAL MATERIAL 2006;964; 1 - 11

[15]. Andrew Joiner.Review of the effects of peroxide on enamel and dentine properties journal of dentistry $2007 ; 35: 889-896$

[16]. Smith HV and John McInnes. Vital tooth whitening . Dent Clin North Am 1966;51(2): 319-331.

[17]. Rodrigues, JA, Basting, RT, Serra, MC, \& Rodrigues, AL Jr. Effects of 10\%carbamide peroxide bleaching materials on enamel microhardness. Am J Dent. 2001;14:67-71.

[18]. BA Matis ,MA Cochran , M FrancoW, Al-Ammar, GJ Eckert, M Stropes. Eight In-office Tooth Whitening Systems Evaluated In Vivo:A Pilot Study@Operative Dentistry, 2007, 32-4, 322-327

[19]. JK Bernardon, N Sartori, A Ballarin J Perdigão, G Lopes , LN Baratieri. Clinical Performance of Vital Bleaching Techniques Operative Dentistry, 2010, 35-1, 3-10 